\title{
Reproductive success of Whiskered Tern Chlidonias hybrida in eastern Spain in relation to water level variation
}

\author{
Alvaro Ortiz ${ }^{\text {Corresp., }}{ }^{1}$, Javier Vidal Mateo ${ }^{1}$, Vicente Urios Moliner ${ }^{1}$ \\ ${ }^{1}$ Department of Environmental Sciences and Natural Resources, Universidad de Alicante, Alicante, Spain \\ Corresponding Author: Alvaro Ortiz \\ Email address: milicora@yahoo.es
}

Background. A study on the Whiskered Tern Chlidonias hybrida was carried out between 2002 and 2009 in wetlands of eastern Spain to evaluate how water level fluctuation affects its reproductive success (hatching, fledgling and breeding success). This species is catalogued as Vulnerable in Spain and has an unfavorable conservation status in Europe.

Methods. Our study includes 18 sampling areas from 5 wetlands, covering a total of 663 nests, 1,618 eggs, 777 nestlings and 225 fledglings. The colonies were visited at least twice per week in breeding period. The number of eggs and/or nestlings present in each nest were annotated each time the colonies were visited with the aim to compare the evolution of these parameters with time. Hatching success was calculated as the proportion of egg that hatched successfully. Fledgling success and breeding success were calculated as the proportion of chicks that fledged successfully and the proportion of eggs that produced fledglings. We used Kruskal-Wallis test to analyze the differences in the dependent variables hatching, fledgling and breeding success among the wetlands and the sampling areas. We explored the relationship between the different reproductive success with the average fluctuation rate and the anchoring depth of nests, using statistics of the linear regression.

Results. It was observed that the reproductive success varied significantly in the interaction among the different categories of water level fluctuation and the different areas (using Kruskal-Wallis test). Our records showed that pronounced variations in water level destroyed several nests, which affected the Whiskered Tern reproductive success. Considering all events that occurred in 18 areas, the mean ( \pm SD) of nests, eggs and nestlings that were lost after water level fluctuations were of $25.60 \pm 21.79 \%, 32.06$ $\pm 27.58 \%$ and $31.91 \pm 21.28 \%$ respectively, including also the effects of rain and predation.

Discussion. Unfavorable climatic events, such as strong wind, rain or hail, also caused the lost of nests, eggs and nestlings, even when wetland water levels remained constant. The influence of the anchorage depth of the nest and the water level fluctuation rate were analyzed and did not provide statistically significant results. It was not possible to establish a clear pattern on these latter variables, so further studies are needed to obtain more significant results. We propose to undertake similar studies in wetlands where water level can be regulated, with the range of nest anchorage depth on the emergent vegetation being between $30-60 \mathrm{~cm}$, what could improve the reproductive success in this kind of habitats. As recommendation, in water level controlled wetlands (that use sluices), it should not vary more than $\pm 6 \mathrm{~cm}$ in a short time (1-2 days) once the nests are established since it negatively affects their reproductive success. 
3

\section{Reproductive success of Whiskered Tern Chlidonias hybrida in eastern Spain in relation to} water level variation

\section{ÁLVARO ORTIZ¹, JAVIER VIDAL-MATEO², VICENTE URIOS ${ }^{3}$}

Department of Environmental Sciences and Natural Resources.

Vertebrates Zoology Research Group

Alicante University

Spain

Corresponding author ${ }^{1}$ : Álvaro Ortiz

e-mail: milicora@yahoo.es

Phone number: + 34672054481

Author $^{2}$ : Javier Vidal-Mateo

e-mail: javier.vidal@ua.es

Author ${ }^{3}$ : Vicente Urios

e-mail: vicente.urios@ua.es 


\section{Abstract}

34

Background. A study on the Whiskered Tern Chlidonias hybrida was carried out between 2002 and 2009 in wetlands of eastern Spain to evaluate how water level fluctuation affects its reproductive success (hatching, fledgling and breeding success). This species is catalogued as Vulnerable in Spain and has an unfavorable conservation status in Europe.

Methods. Our study includes 18 sampling areas from 5 wetlands, covering a total of 663 nests, 1,618 eggs, 777 nestlings and 225 fledglings. The colonies were visited at least twice per week in breeding period. The number of eggs and/or nestlings present in each nest were annotated each time the colonies were visited with the aim to compare the evolution of these parameters with time. Hatching success was calculated as the proportion of egg that hatched successfully. Fledgling success and breeding success were calculated as the proportion of chicks that fledged successfully and the proportion of eggs that produced fledglings. We used Kruskal-Wallis test to analyze the differences in the dependent variables hatching, fledgling and breeding success among the wetlands and the sampling areas. We explored the relationship between the different reproductive success with the average fluctuation rate and the anchoring depth of nests, using statistics of the linear regression.

Results. It was observed that the reproductive success varied significantly in the interaction among the different categories of water level fluctuation and the different areas (using KruskalWallis test). Our records showed that pronounced variations in water level destroyed several nests, which affected the Whiskered Tern reproductive success. Considering all events that occurred in 18 areas, the mean $( \pm \mathrm{SD})$ of nests, eggs and nestlings that were lost after water level fluctuations were of $25.60 \pm 21.79 \%, 32.06 \pm 27.58 \%$ and $31.91 \pm 21.28 \%$ respectively, including also the effects of rain and predation.

Discussion. Unfavorable climatic events, such as strong wind, rain or hail, also caused the lost of nests, eggs and nestlings, even when wetland water levels remained constant. The influence of the anchorage depth of the nest and the water level fluctuation rate were analyzed and did not 
63 provide statistically significant results. It was not possible to establish a clear pattern on these 64 latter variables, so further studies are needed to obtain more significant results. We propose to

65 66

72 undertake similar studies in wetlands where water level can be regulated, with the range of nest anchorage depth on the emergent vegetation being between $30-60 \mathrm{~cm}$, what could improve the reproductive success in this kind of habitats. As recommendation, in water level controlled wetlands (that use sluices), it should not vary more than $\pm 6 \mathrm{~cm}$ in a short time (1-2 days) once the nests are established since it negatively affects their reproductive success.

\section{Introduction}

The population of Whiskered Tern Chlidonias hybrida (Pallas, 1811), a migratory species of the family Sternidae, have declined in the Iberian Peninsula and Europe from 1970 to 1990 (Urios et al., 1991, Tucker \& Heath, 1994). It is catalogued as an Endangered Species in Spain, according to Real Decreto 139/2011 (BOE 2011), and has an unfavorable conservation status in Europe (Tucker \& Heath, 1994), as it is included in the priority conservation of wild birds directive (BirdLife, 2004).

Between 1990 and 2000, their populations remained relatively stable in Europe, with clear increases in the central and eastern parts of the continent, comprising ca. 87,000 pairs (BirdLife, 2004). In 2015, their populations have been estimated between 66,300-108,000 pairs in Europe and ca. 6,400 pairs in Spain (Birdlife 2015). The future of the species in the Iberian Peninsula appears to be uncertain due to habitat destruction (Callaghan \& Villaplana, 1990), urban pressure and the reduction of wetlands due to their transformation in agricultural areas (Villaplana, 1984; Callaghan \& Villaplana, 1990; Urios et al. 1991), as well as the increase in pollution and loss of water quality (Blanco \& González, 1992), the inadequate management of water reservoirs and lagoons, and climatological factors (Máñez et al., 2004). In the natural wetland of Albufera of Valencia (39²0'05" N, 0² $21^{\prime} 08^{\prime \prime} \mathrm{W}$, SE Spain) that includes 21,120 ha, about 2,000 pairs of Whiskered Terns nested in 1970. Since then, an important decline of nesting pairs occurred, and in 1980 no more nesting pairs were observed in that area (Urios et al., 1991). Since 1980 to the present the species did not nest in the Albufera of Valencia, although it has been observed resting in this area while migrating.

The reproductive success of the Whiskered Tern greatly depends on numerous factors such as the 
94 chosen area for reproduction by parents, the reproduction in colonies or as isolated nests, the

95 climatic conditions, the water level variation in the wetlands and its stability during the

96 reproduction period, the abundance of food (Tucker \& Heath, 1994; Catry et al., 1997;

97 Carpentier et al., 2002); the type, form and size of the nests, the presence of parasites and

98 predators, the type of vegetation on which the nests are anchored and its abundance (Spina,

99 1982; Dostine \& Morton, 1989; Bakaria et al., 2002; Latraube, 2006; Paillisson et al., 2006;

100 Bakaria et al., 2009; Ledwoń et al., 2014); and the quality of cares that parents provide to their

101 descendence (Nichols et al., 1990; Spendelow et al., 1995, Brunton, 1997; Lebreton et al., 2003;

102 Paillisson et al., 2007; Alvarez \& Barba, 2008; Monticelli et al., 2008; Braasch et al., 2009;

103 Ledwoń et al., 2013). When all these conditions are suitable, the reproductive success is usually

104 high.

105 As a fragile medium disturbance species, adverse conditions in the breeding season force the

106 populations to abandon the colony (Spina, 1982; Catry et al., 1997; Bakaria et al., 2002;

107 Paillisson et al., 2006; Ledwoń et al., 2011), which cause the loss of nests, eggs and nestlings;

108 force second clutches (Catry, 1997; Ortiz, 2005); or cause migration to other areas with more

109 sheltered habitats, and enough available food and water for nesting (Paillisson et al., 2007). This

110 has been observed also in other species of the same family (Buckley \& Buckley, 1972; Nisbet et

111 al., 1995; Stienen \& Brenninkmeijer, 2002; Van de Pol et al., 2010).

112 The main aim of our study was to study the reproductive success of the Whiskered Tern in

113 relation to water level variability. We consider the hypothesis that a strong variation of water

114 level in a short period of time could negatively affect breeding success. Nests of this species are

115 anchored to emergent vegetation (such as: Phagmites sp., Thypha sp, Scirpus sp., Myriophyllum

$116 s p$.), and therefore changes in the water level in the wetlands where they breed could negatively

117 affect to its reproductive success, since eggs or nestlings could be lost in that process (Van de Pol

118 et al., 2010). This also occurs in other species of the Sternidae family due to natural hydrological

119 regimes that changes the shape of the colonies, their distribution and the number of individuals in

120 a wetland (Atamas \& Tomchenko, 2015).

121 We expect that our study will bring new knowledge to enhance the management and

122 conservation of the species in the wetlands where the species nests, that could serve as a model

123 for management in other areas, and we discuss recommendations for the conservation of

124 Whiskered Terns. 


\section{Study Area \& Methods}

127

\section{Study Area}

129 The present study was carried out during eight breeding seasons (2002-2009) of Whiskered Tern

130 in the Pego-Oliva Natural Park (Valencian Community, Spain). Additional observations were

131 made at four further wetlands in Valencian Community: Hondo de Elche-Crevillente N.P.

132 (Alicante), Xeresa marsh (Valencia), Moro marsh (Valencia) and Almenara marsh (Castellón).

133 These latter wetlands are located between 20 and $100 \mathrm{~km}$ from Pego-Oliva Natural Park in

134 straight line (Fig. 1). Valencian Community government and managers of the Natural Parks

135 involved in this study provided permissions to work in the cited wetlands.

136 The Pego-Oliva Natural Park is located in northeastern Alicante Province (38'52'50'N,

137 0'04'09''W; Fig. 1) and comprises ca. 1,290 ha in total. Among them, the permanent wetland

138 areas sum ca. 800 ha. In a period of 30 years (1961-1990) the mean annual precipitation is 817

$139 \mathrm{~mm}$, however in our studied period (2002-2009) this mean was 1,014 $\mathrm{mm}$. These latter years

140 were of large water affluence, where the average in our study period exceeded by $200 \mathrm{~mm}$ the

141 average of 3 previous decades. The mean annual temperature is ca. $17^{\circ} \mathrm{C}$, however in our studied

142 period this mean was $19.5^{\circ} \mathrm{C}$, with the maximum monthly mean temperatures being $30.8^{\circ} \mathrm{C}$ in

143 July and August, with the absolute maximum temperature recorded of $43^{\circ} \mathrm{C}$ in July (1961-1990).

144 The mean temperature in July was $25.1^{\circ} \mathrm{C}$ (mean period 2002-2009), fitting with the species

145 requirements of at least $20^{\circ} \mathrm{C}$ mean temperature in July for breeding (Cramp, 1985). Large

146 extensions of the wetlands are currently occupied by rice fields. The dominant plant species in

147 the wetlands of the Valencian Community that are used by the Whiskered Tern to build their nest

148 are Phragmites australis, Thypha dominguensis, T. latifolia, Scirpus tabernaemontani and $S$.

149 maritimus, being very similar to those found in other studied areas in Iran (Barati et al., 2011a).

150 Other species also occur in the area, such as Tamarix gallica in adjacent areas to the wetlands,

151 and interesting aquatic vegetation in the channels and ponds, such as Myriophillum verticillatum,

152 Potamogeton sp. or Chara sp.

153 The Hondo Natural Park (38 $\left.11^{\prime} 20^{\prime \prime} \mathrm{N}, 0^{\circ} 45^{\prime} 12^{\prime \prime} \mathrm{W} ; 2,495 \mathrm{ha}\right)$, had an average annual precipitation

154 of $300 \mathrm{~mm}$ in the years of study, being 3 times less than the average in the Pego-Oliva N.P. The

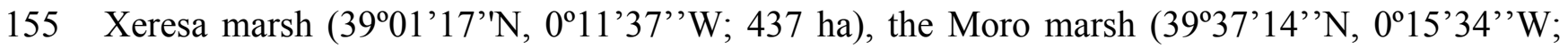


$156800 \mathrm{ha})$ and the Almenara marsh (39 $44^{\prime} 53^{\prime \prime}$ N, $0^{\circ} 11^{\prime} 17^{\prime \prime} \mathrm{W}$; 1,497 ha; Fig. 1). All these wetlands

157 present similar habitats than for the Pego-Oliva N.P. (although lacking rice fields), with suitable

158 vegetation to build and anchor their nests and relatively stable water levels, and therefore are also

159 chosen by the Whiskered Tern to breed.

160

161 Methods

162 The reproductive success (hatching, fledgling and breeding success) of the species was studied in

163 relation to water level variation either produced by sudden climatic changes or hydrological

164 regimens, such as continuous rain or hail, or anthropogenic causes such as marsh draining to

165 irrigate crops or channeling works near the breeding area.

166 From 2003 to 2008 in Pego-Oliva N.P. it was tried to control water level fluctuations and

167 maintain it as stable as possible, using sluices in the channels that supply water from the marsh to

168 the breeding area. However, it was not always possible since large amounts of water entered to

169 the marsh by rain, surface runoff, and rivers flow, which exceeded the water discharge from the

170 marsh and quickly raised water levels.

171

172 Data collection.

173 Depending on the area and colony evolution, wetlands and colonies were visited once a week to

174 record data, when the birds arrived to the wetlands for colony establishment (April-May). Visits

175 were extended twice per week from egg-lay to hatching period (May-July); at least twice per

176 week from the first egg laid (June-July) to fledgling time (a chick needs ca. 21 days to fly), and

177 once or twice per week (depending of the colony) in the fledglings' period (June-August). Nest

178 monitoring was carried out using labeled wooden stakes, on which the number of the nest was

179 marked. We tried to reduce the working time in the colony to minimize possible disturbance to

180 the nests and nestling.

181 We also established a typology on the quality of the nests to explore whether the nest structure

182 affect to the hatching success, differenciating among high, medium and low nest quality. High

183 quality nests were considered those that formed a platform made with fragments of different

184 plant species which were weaved together to form a solid, concave structure above water level

185 (Fig. 2A). Medium quality nests were considered those with platforms above water level but

186 formed with fragments of vegetation not tightly weaved and there is no evident concave central 
187 structure to support the eggs. This category usually included nests set on floating rizhomes of

188 Phragmites sp. and even fallen Tamarix sp. branches (Fig. 2B). Finally, low quality nests were

189 those with very low density of vegetation fragments that leave the eggs very exposed, which can

190 roll and easily fall to the water (Fig. 2C \& 2D).

191 To take census of pairs, nests, eggs and nestlings, researchers directly accessed the breeding

192 colonies, on foot or by an inflatable boat. The number of eggs and/or nestlings present in each

193 nest were annotated each time the colonies were visited with the aim to compare the evolution of

194 these parameters with time. Several nestlings were ringed in the studied colonies with the

195 capture-mark-recapture method. To reduce the underestimation, nestlings were carefully

196 searched while approaching to the nests. In some cases, colonies were observed from the

197 distance with binoculars where vegetation was not an obstacle. With the aim of counting also the

198 chicks that were not in the nests at census time, researches waited for 5-20 minutes at a certain

199 distance to annotate the chicks that return to the nests after entry to the colony by researchers.

200 Fledglings were counted when they and their parents left the nests flying after researchers

201 approach to each nest. In some occasions, with adverse climatologic conditions, it was not

202 possible to observe the fledglings, since the parents moved the chicks to other areas, some times

203 more than $1 \mathrm{~km}$ apart from the original breeding area, and sometimes to other wetland.

204 To avoid understimation of the reproductive success, a trapping technique could have been used

205 for chicks census, as proposed by Ledwoń et al. (2015), which does not affect to the breeding

206 success (Ledwoń et al. 2016). However, we rejected the idea of using trapps in our study to

207 decrease the anthropic impact on the colony that could affect to the reproductive success results.

208 Nestlings leave nest temporarily when they are 3-10 days old and seek refuges away from it,

209 moving further if disturbed (Cramp, 1985, Muzinić \& Delić, 1997), and often return to it

210 afterwards (Paillisson et al., 2008).

211 Criteria to what is considered a fledgling varies from different authors. Barati et al. (2011a)

212 consider fledgling to a nestling unless it was found dead around the nest. Brunton (1997)

213 consider a nestling like a fledgling at the age of 14 days old in the Sterna sp. Bollinger (1988)

214 say that chicks of Sterna hirundo older than 10 days old have a 90\% chance of becoming

215 fledglings. However, Van de Pol et al. (2010) consider that in gull, common tern and avocet

216 chicks younger than 14 days old, are at risk of drowning or hypothermia. For calculations on our

217 study, fledglings were considered as those individuals older than 10-12 days old. In addiction, if 
218 the chick has left the nest, their parents must remain near the original nest, and then the nest

219 should be in good conditions due to parents care. Moreover, we should know if the nest was

220 active, annotating when the nests were abandoned, in relation to the structure of nests and the

221 presence of freshly added vegetation to maintain the nest floating.

222

223 Parameters studied

224 During the 8 years of study in the Valencian Community, 94 samplings were carried out in 14 225 different colonies, some of them with subcolonies (a total of 18 sampling areas). The following 226 direct observations were made: the number of nests, the number of eggs, the number of nestlings,

227 the number of fledglings, the date of the first fledglings, and the date when the adults with

228 fledglings left the colony (that sometimes helped us to calculate the number of fledglings in 229 some colonies). However, these results include all the variables that may affect these results, 230 such as rainfall, changes in water fluctuation, predation, and nest anchoring depth.

231 To calculate the survival percentage of nests in the different localities along the whole study 232 period the method Mayfield was used. Hatching success was calculated as the proportion of eggs 233 that hatched successfully. Fledgling success and breeding success were calculated as the

234 proportion of chicks that subsequently fledged successfully and the proportion of eggs that 235 produced fledglings.

236 Mean values are given with \pm SD. Obtained data on the studied parameters are expressed as total 237 mean values for the 8 years of study. The percentage of hatching, fledgling and breeding success 238 were calculated for every nest.

239 The average percentage of loss of eggs, nests and chicks in each sampling for each year and area 240 were also calculated.

241 Water level fluctuations were also recorded in the cited wetlands to study its influence on the 242 colony and its correlation with the reproductive success, as well as the depth to which the nests

243 were anchored. Permanent wooden stakes calibrated in centimeters were used to observe the 244 water level fluctuations and the depth.

\section{Analitical Procedures}

247 We wanted to compare the correlation between the average daily water fluctuation rate (measure 248 based on the water height) and the reproductive success, and between the anchoring depth of nest 
249 and the reproductive success. For this, we performed a regression analysis relating the

250 percentage of hatching, fledgling, and breeding success with the average daily fluctuation rate

251 and the depth, for the selected areas and the 8 years of study, among the total nests and among

252 nests of each area. The daily fluctuation rate ( $\mathrm{cm} /$ day) is given by the division of the water level

253 fluctuation with respect to the sampling interval.

254 Data failed the test for normality (Kolmogorov-Simirnov test), so we used Kruskal-Wallis test to 255 compare the dependent variables (hatching, fledgling and breeding success) among the five 256 studied wetlands and the 18 sampling areas. We also compared the differences in the percentage

257 of nests, eggs and chicks loss between the areas and years. All statistical analyses were 258 performed with IBM SPSS Statistics ver. 22.0. Significance level was established at $\mathrm{p}<0.05$. 259

260

\section{Results}

261

\section{Reproductive success}

263 In all wetlands studied in the Valencian Community (2002-2009), a total of 663 nests, 1618 eggs, 264777 nestlings and 225 fledglings were counted.

265 The mean $( \pm \mathrm{SD})$ survival percentage of nests among the different localities in the whole studied 266 period using the Mayfield method was $61,7 \pm 27 \%$.

267 The mean $( \pm \mathrm{SD})$ of the percentages of hatching obtained in high quality nests $(\mathrm{n}=65)$ was $44.1 \pm$ $26843.4 \%$; in medium quality nests $(n=120)$ was $38.1 \pm 37.9 \%$; and in low quality nests $(n=28)$ was $26929.8 \pm 38.3 \%$. The total hatching success in all studied areas was: high quality was $39.38 \%$, 270 medium quality was $34.02 \%$ and low quality was $26.60 \%$.

271 Considering all colonies studied, the total mean percentage of hatching success ( \pm SD) was of $27249.0 \pm 25.8 \%(\mathrm{n}=663)$ with a total mean of clutch size $( \pm \mathrm{SD})$ of $2.37 \pm 0.27$ eggs $/$ nest. The mean 273 of nestling $( \pm \mathrm{SD})$ per nest was $1.1 \pm 0.6$. The total mean percentage of fledgling success $( \pm \mathrm{SD})$ 274 was $29.1 \pm 21.9 \%$ with a mean of fledgling $( \pm \mathrm{SD})$ per nest of $0.49 \pm 0.4$. The total mean 275 percentage of breeding success $( \pm \mathrm{SD})$ was $21.8 \pm 18.9 \%$ (Table 1 ). The hatching success, as 276 well as the fledgling and breeding success varied significantly among wetlands and among 277 sampling areas, according to the Kruskal-Wallis test (Table 2).

278 In Pego-Oliva N.P., the area with data for the 8 years of study, a total of 369 nests, 885 eggs, 493 279 nestlings and 136 fledglings were counted. The mean of clutch size $( \pm \mathrm{SD})$ was $2.35 \pm 0.31$ 
280 eggs/nest. The total mean percentage of hatching success $( \pm S D)$ was $47.5 \pm 25.7 \%(n=368)$,

281 varying significantly among years (Kruskal-Wallis test: $\mathrm{H}(7, \mathrm{~N}=663)=90.24761 ; \mathrm{p}<0.0001)$,

282 from $90 \%$ in years with favorable conditions to $10 \%$ in years with unfavorable conditions \%

283 (Table 1; Fig. 3). The mean of nestlings $( \pm \mathrm{SD})$ per nest was $1.1 \pm 0.6$. The total mean percentage

284 of fledgling success $( \pm \mathrm{SD})$ was $25.7 \pm 19.0 \%$, also varying significantly among years (Kruskal-

285 Wallis test: $\mathrm{H}(7, \mathrm{~N}=663)=84.53519 ; \mathrm{p}<0.0001)$, with a mean of fledglings $( \pm \mathrm{SD})$ per nest of

$2860.43 \pm 0.3$. The total mean percentage of breeding success $( \pm \mathrm{SD})$ over the eight years was $17.7 \pm$

$28713.6 \%$, and it also varied significantly among years (Kruskal-Wallis test: $\mathrm{H}(7, \mathrm{~N}=663)$

$288=78.77938 ; \mathrm{p}<0.0001)$.

289

290 Anchoring Depth

291 The total depth average $( \pm$ SD) where the nests were anchored in all sampling areas was $44.1 \mathrm{~cm}$

$292 \pm 18.2 \mathrm{~cm}(\mathrm{n}=18$ colonies), with a common range between 25 and $80 \mathrm{~cm}$. We recorded some

293 nests in the Almenara marsh (2008) that were built in areas with a water depth of ca. $200 \mathrm{~cm}$,

294 being anchored on the algae Cladophora sp. attached to Myriophyllum verticillatum, but we did

295 not obtain data from that colony.

296 It was considered whether a correlation exists between the water depth in which the nests are

297 anchored over macrophytes and the hatching, fledging and breeding success, since depths

298 strongly varied among the studied colonies. However, we did not find a correlation among the

299 water depth and reproductive success considering all nests, showing a $\mathrm{R}^{2}<0.1$ (Table 3; Fig. 4A,

300 B \& C). The same occurred differentiating the nests by wetlands, with $\mathrm{R}^{2}<0.2$. This calculation

301 was only done for Pego-Oliva N.P. and Moro wetland, since in Hondo, Xeresa and Almenara we

302 did not obtain enough data for a regression.

303

304 Daily rate of fluctuation against the percentages of nests, eggs and chicks loss.

305

306 The total mean percentage ( \pm SD) of lost eggs in the studied wetlands in the Valencian

307 Community was $51.6 \pm 25.2 \%$ with a total of $n=841$ lost eggs and a mean $( \pm$ SD) of $46.7 \pm 47.2$

308 eggs/colony. The total mean percentage $( \pm \mathrm{SD})$ of lost chicks was $56.0 \pm 25.7 \%$ with a total of

$309 \mathrm{n}=552$ (Table 4$)$ and a mean $( \pm$ SD) of $30.67 \pm 39.28$ chicks/colony.

310 In Pego-Oliva N.P., the total mean percentage ( \pm SD) was $53.3 \pm 25.1 \% \mathrm{n}=392$ lost eggs and a 
311 mean of $35.6 \pm 27.1$ lost eggs per colony. The mean percentage $( \pm$ SD) of lost chicks was 57.45

$312 \pm 27.68 \%$ with a total of $n=357$ a mean $( \pm$ SD) of $32.45 \pm 43.36$ chicks /colony.

313 Although reproductive success does not have a homogeneous variability, it was observed (using

314 Kruskal-Wallis test) that the reproductive success varied significantly in the interaction among

315 the different daily rate of water level fluctuation and the different areas (Table 3).

316 The mean percentage of nests, eggs and chicks loss ( \pm SD) was of $25.60 \pm 21.79 \%, 32.06 \pm$

$31727.58 \%$ and $31.91 \pm 21.28 \%$ respectively (Table 4 ), although some of these values varied

318 significantly among colonies and years (Table 5). The percentage of eggs loss was different

319 among colonies and years, and the chicks loss was different among years.

320 In some years there were almost no losses of nests with values of $1.82 \%$ while in other years the

321 loss has been almost absolute with maximums of $90 \%$. The same patterns occurred with eggs

322 and chicks obtaining minimums of $13.1 \%$ and $6.2 \%$ respectively and maximums of $90 \%$ and

$32376.1 \%$ respectively (Table 4 ).

324 Considering the studied variables, according to the linear regressions there is no correlation

325 among the hatching, fledgling and breeding success and the average daily fluctuation rate, with

$326 \mathrm{R}^{2}<0.1$ (Table 3; Fig. 4D, E \& F). However, a tendency was observed on absolute values of

327 maximum water level fluctuation that exceed $8 \mathrm{~cm}$ that caused a decrease in the hatching and

328 fledgling success percentages. This pattern is even more evident when the maximum water level

329 fluctuation during the whole breeding period is more pronounced (Table 1).

330

\section{Discussion}

332

333 Whiskered Tern breeded in wetlands of the Valencian community almost every year in the last

334 decades. Each year this species searched for the most suitable areas for breeding, coming back

335 the following year to the same breeding area when the environmental conditions were suitable.

336 This same pattern was observed by Burger and Shisler (1980) in a study on the laughing gulls

337 (Larus atricilla), where the reproductive success was directly related to nest location.

338 Our results on the water depth range where the Whiskered Tern anchors their nests in the whole

339 study period in the Valencian Community (between 25 and $80 \mathrm{~cm}$ ) was similar to those observed

340 in other studies which ranged commonly between 60-80 cm (Cramp 1985), although Barati et al.

341 (2011b) also found nests in deeper waters $(164 \pm 30 \mathrm{~cm})$, which depended on the type of aquatic 
342 vegetation. We did not find a clear correlation among the water depth and hatching, fledging and

343 breeding success (Table 3; Fig. 4A,B,C), probably due to the variety of factors that can influence

344 the breeding, such as the kind of plants used for the nesting or the rain.

345 Our study, including our field observations, evidence that the quality of the nests and the quality

346 of the cares that the parents provide to their descendence affect to the hatching success. For

347 instance, a higher nest quality increase the reproductive success, as it was also observed by other

348 authors in this family of birds and of others species (Nichols et al., 1990, Bakaria et al., 2002;

349 Paillisson et al., 2006; Alvarez \& Barba, 2008; Monticelli et al., 2008; Ledwoń et al., 2013).

350 The annual average clutch size (number of eggs per nest) obtained in the Pego-Oliva N.P. was

$3512.35 \pm 0.31$ (SD, $\mathrm{n}=369$ ), being similar those obtained in other studies, such as in Portugal, that

352 showed averages of $2.91(\mathrm{n}=45)$ in 1993 and $2.95(\mathrm{n}=39)$ in 1994 (Catry et al., 1997), and in

353 Croatia $2.64 \pm 0.77(\mathrm{SD}, \mathrm{n}=253$ ) in 1993 (Muzinić \& Delić, 1997). In other studies in France

354 annual average clutch size was $2.71 \pm 0.49(\mathrm{SD}, \mathrm{n}=211)$ in $2004 ; 2.05 \pm 0.78(\mathrm{SD}, \mathrm{n}=406)$ in

3552005 (Paillisson et al., 2006) and $2.35 \pm 0.05$ (SE, $\mathrm{n}=207)$ in 2006 (Paillisson et al., 2008).

356 Similar studies in Iran obtained averages of clutch size of $2.39 \pm 0,1(\mathrm{SE}, \mathrm{n}=53)$ in 2005 (Barati et

357 al., 2011a).

358 The mean $( \pm$ SE) of chicks that become fledglings in all studied wetlands was $0.5 \pm 0.1$

359 chicks/nest per year, with $n=663$ nests. These results are similar to those obtained in other studies

360 in Iran, such as $0.66 \pm 0.11$ chicks, with $\mathrm{n}=68$ in 2008 (Barati et al, 2011), although this same

361 author obtained in 2007 a mean of $1.65 \pm 0.14$ chicks with $n=75$.

362 In the Pego-Oliva P.N. wetland, the mean ( \pm SD) percentage of nests with one egg (between

3632002 and 2009) was $8.7 \pm 10.7 \%$; with 2 eggs $38.8 \pm 29.7 \%$; with 3 eggs $41.6 \pm 32.7 \%$; and

364 with 4 eggs $0.9 \pm 1.5 \%$. There are some studies in which the clutches with 5 eggs or more per

365 nest are $0.3 \%$ of nests in Chlidonias hybrida, $1.8 \%$ in Larus cachinnans and $4.1 \%$ in $L$.

366 melanocephalus (Betleja et al. 2007). Muzinć \& Delić (1997), in a study on C. hybrida and 105

367 nests, obtained percentages of $10.5 \%$ with 1 egg; $17.1 \%$ with 2 eggs; $60 \%$ with 3 eggs; $2.9 \%$

368 with 4 eggs; and $0.9 \%$ with 5 eggs, counting also the nests with no eggs, being 8.9\% in 1993.

369 Our study, including all 18 colonies and the whole period studied, obtained a mean of clutching

370 success of $49.0 \pm 25.8 \%, n=663$ nests, being very similar to that obtained for the Pego-Oliva

371 N.P. alone, which was of $47.5 \pm 25.7 \%, n=369$ nests, with significant differences among

372 colonies, years and areas, varying from 10\% and 90\% (Table 1). Other studies showed much 
373 higher clutching success. For example, Bakaria (2013), in his studies in Algeria, obtained a mean

$374( \pm$ SD) of clutching success of $82.9 \pm 34.35 \%$ in $2005, n=302$ nests and $76.6 \pm 38.9 \%$ in 1996 ,

$375 n=169$ nests. Amini-Nasab et al. (2004) in Iran obtained percentage between 57 and 83\%. In

376 Croatia, Mužinić \& Delić (1997) found a mean of 88\%, n=96, and Ledwoń (2017) 82.9\% in

377 various studies in Poland between 2006 and 2015. In other continents, clutching success was

$37871 \%$ in the Volga in Russia, or $65.6 \%$ on Chlidonias hybrida javanicus in Australia (Cramp \&

379 Simmons, 1977).

380 Our low percentage of clutch success with regards to similar studies in other countries, as

381 mentioned above, can be explained by the nature of the vegetation on which the Whiskered Tern

382 anchor their nests. In our study area, nests are anchored on delicate floating vegetation, such as

383 Myriophyllum sp., on the ground in shallow waters by accumulations of vegetation fragments

384 above water level, or on fixed vegetation such as Phragmites sp. or Typha sp. Therefore, nests

385 are strongly affected by water level fluctuations as they are not able to move vertically and eggs,

386 chicks or fledglings can be damaged. On the contrary, nests in other countries are usually set on

387 solid floating vegetation, such as Nymphoides peltata (Gwiazda \& Ledwoń, 2015) or Nymphaea

388 alba (Paillisson et al., 2006) and therefore water level fluctuations do not strongly affect to the

389 nests as these are able to adapt water level variation by floating, and therefore clutching success

390 increase.

391 The eggs, nestlings and fledglings loss caused by predators were not considered independently in

392 our study mainly due to technical problems to record those data, and therefore must be assumed

393 to be included in our total loss data, although we assume that they were low as pointed out in our

394 statistical analyses.

395 Only in 2003 in the Pego-Oliva N.P., where the climatic conditions and water level fluctuations 396 were stable, a percentage of eggs loss was calculated, most probably due to predation. A total of

39711 eggs were lost from $n=153$ eggs, being a total of $7.2 \%$ of eggs loss. However, we do not have

398 evidences that all eggs were predated and probably some of them felt to the water by parents

399 activities. Studies in Croatia in 1993 with $n=253$ eggs in 22 nests showed $8.7 \%$ of eggs loss

400 probably due to predation (Muzinć \& Delić, 1997).

401 A colony with synchrony helps against predation (Cramp, 1985; Quintana \& Yorio, 1997) and

402 some studies evidence that peripherial nests present lower reproductive success than those in the

403 centre of the colony (Wittenberger \& Hunt, 1985, Brown \& Brown, 1987, Wiklund \& 
404 Andersson, 1994, Minias et al., 2013), although other studies do not support this conclusions 405 (Brunton, 1997). In our studies, depending on the year and the vegetation cover, the nests were more concentrated or dispersed, even in different areas with different depths.

407

\section{Hatching, fledgling and breeding success in relation to the water level fluctuations.}

409

410 Although some authors have reported the abandonment of the eggs layings when water level

411 fluctuations are severe (Catry et al., 1997; Paillisson et al., 2006; Ledwoń et al., 2013), in our

412 study no significant differences are observed for hatching success in relation to water level

413 fluctuations rate (Table 3; Fig. 4D, E \& F). A mean of ca. 50\% hatching success has been found

414 in most of our studied wetlands, excepting the Hondo N.P. with a 19\%, due to channelling works

415 that caused the loss of many layings (Table 4). It has been also observed a large variability

416 (heterocedasticity) in the water level fluctuations in all studied wetlands.

417 In the same way, no significant differences have been observed in the fledgling and breeding

418 success in relation to water level fluctuations and considering the different wetlands studied.

419 In general, a large variability exists in the breeding success, considering both eggs and nestlings

420 that probably are influenced by other factors not considered in this study. From 1618 eggs censed

421 in the 18 colonies in all years and areas in our study, 841 eggs (51.97\%) were lost. This can be

422 explained by the role of other factors that influence the hatching success, such as the direct effect

423 of rain, hail or predation or the low quality of the parents care on the eggs that were not included

424 in the statistical models. It has been also observed that the hatching success in some colonies was

425 not affected by the water level fluctuation, due to the fact that the parents are able to reconstruct

426 the nests while progressive water level fluctuations and the eggs and or nestlings survive.

427 Following Bayard \& Elphick (2011), the increase of the water level in marshes and breeding

428 areas of Ammodramus caudacutus is one of the main causes of low breeding success, as it also

429 occurs with Chlidonias hybrida.

430 We also observed that unfavorable climatic events, such as intense rain, hail, or wind or streams

431 of water caused by human activities, also had the capacity to disrupt incubation or the destruction

432 of nests, the loss of many layings and even the abandonment of the whole colony. In two 433 occasions (in the years 2005 and 2008) in Pego-Oliva N.P, the rain with hail at the beginning of 434 the summer destroyed many nests, and watering of crops in Xeresa marsh in 2005 desiccated 
435 completely the wetland causing the loss of most layings. Channeling works (as occurred in 436 Hondo N.P. in 2005) using heavy machinery also caused the decrease of the water level in some 437 areas which affected the anchored nests. Furthermore, in some occasions, colonies were 438 damaged by streams of water caused by the transfer of masses of water within the wetlands by 439 human activities, although water level remained more or less constant. All these events caused 440 the loss of high percentages of nests, eggs and nestling, forcing the parents to produce second 441 clutches or to abandon the colony, moving to a different feeding area, like Albufera of Valencia 442 (Fig. 1) or other wetlands.

443 This behaviour was also reported by Rizi (1994), Tomialojć (1994), Elkins (1996), Bakaria 444 (2002), Amini Nasab et al. (2004), Máñez et al. (2004a), Van de Pol et al. (2010) and Ledwoń 445 (2013), being similar to the results obtained from studies on Chlidonias niger (Chapman-Mosher 446 1978) where losses caused by severe precipitations were $37 \%$.

447 In our study, the total percentage mean loss of nests, eggs and chicks ( \pm SD) among the 94 448 sampling period was $25.60 \pm 21.79 \%, 32.06 \pm 27.58 \%$ and $31.91 \pm 21.28 \%$ respectively (Table 449 4).

450 We observed that colonies with severe maximum water level fluctuation during the nesting 451 period usually have low reproductive success (Table 1). In the colonies where this was not 452 reflected, it was due to the fact that fluctuations did not directly damage the laying eggs in the 453 breeding period due to the parents care. In years where there were major water level fluctuations 454 and heavy rain, the percentages of hatching, fledgling and breeding success in Pego-Oliva N.P. 455 were lower (with a breeding success very low, varying from $1.8 \%$, in 2003 to $11.1 \%$ in 2005). 456 In 2003, 2004 and 2009, where conditions were very favorable, the breeding success was higher, 457 being $28.2 \%, 29.4 \%$ and $26.6 \%$ respectively (Table 1 ).

458 In the figure 5, two nests can be observed, one with 3 eggs and a high quality structure (Fig. 5A) 459 and another one destroyed after the water level rise (17-22 July 2002), in which the level rose 460 more than $7 \mathrm{~cm}$ (Fig. 5B). In addition, there was evidence of water run in the lagoon. Nests of 461 medium or low quality were commonly found destroyed after severe water level fluctuations, 462 differing from nests of high quality that in general resisted better water level fluctuations.

463 We could not determine a specific value for the survival of the nests, where the loss of nests, 464 eggs and nestlings remained stable, as it depends on each colony, event from each year and the 465 vegetation where nests were anchored. In general, our data indicate that water level fluctuations 
$466>6 \mathrm{~cm}$ affected moderately to the colony and values above $10 \mathrm{~cm}$, affected severely to the

467 Whiskered Tern reproductive success. Sudden and severe water level fluctuations cause either

468 the placement of the anchored nests above water level or being submerged in the water,

469 hindering or making impossible nest access for nestlings or losing the eggs. These results are

470 similar to those obtained by Van de Pol et al. (2010) who found that water level fluctuation

471 between 10 and $20 \mathrm{~cm}$ in species of family Sternidae strongly affect to the chicks that are not

472 able to return to the nest and may die due to hypothermia or drown.

473

474 Conclusions

475 It was not possible to establish a clear pattern among water level fluctuation and breeding

476 success, so further studies are needed to obtain more significant results. We propose to undertake

477 similar studies in wetlands where water levels can be regulated, with the range of depth of the

478 anchorage of nests on the emergent vegetation being between 30-60 cm, what could improve the 479 reproductive success.

480 As a recommendation, in water level controlled wetlands (that use sluices), for Whiskered Tern

481 habitat management, and based on our observations, it is essential that the water level remains as

482 stable as possible in the breeding season, which should not sharply vary more than $\pm 6 \mathrm{~cm}$ in a

483 short time period (1-2 days) once nests are anchored on the aquatic vegetation (such as:

484 Phagmites sp., Thypha sp, Scirpus sp., Myriophyllum sp.), since this could cause in the

485 destruction of nests and therefore the loss of eggs and nestlings although in our study it has not

486 been possible to extract a clear pattern.

487 Most wetlands in the Valencian Community have sluices that serve to drain areas and irrigate

488 adjacent crops, therefore they often have locks to distribute the water through channels. Once the

489 date of incubation and nestling growth is known, introducing some synchrony in the nest, we

490 could manage those risks or canalization works, etc, to be postponed to times out from the

491 breeding season, and thus, this could minimize the impacts on the Whiskered Tern laying eggs.

492 Finally, we confirmed that despite having stable water levels, the spring and summer rains were

493 causing the abandonment of the clutches repeatedly.

494

495 Acknowledgements

496 
497 With special reference to: Mario Martínez Azorín for his unconditional support. Maria Cristina

498 Lorenzo for her support in the final stages of my work. To my family and friends for being

499 always there. Javier García Gans for contributing to ringing. Pascual Lopez for his contribution

500 in statistics. To Juan Jimenez for providing me old data and gave me permission to come in

501 wetlands (Conselleria d'Infraestructures, Territori i Medi Ambient. Generalitat Valenciana). To

502 Martin Haubeck (Seabird Journal Editor), for his first review.

503

504 References

505

506 Álvarez E, Barba E. 2008. Nest quality in relation to adult condition and its impact on

507 reproduction in Great Tits Parus major. Acta Ornithologica Journal 43: 3-9

508 Amini Nasab, S.M., Behroozi Rad, B. \& Riahi Bakhtiari, A.R. 2004. Reproductive phenology

509 and breeding success on the whiskered tern (Chlidonias hybridus) in southern of Caspian Sea

510 Ab-bandans (artificial wetlands) in the north of Iran (Mazandaran province). Section 5: Caspian

511 Sea: Ecology and Biology.

512 Atamas NS, Tomchenko OV. 2015. The Influence of spring flood water levels on the

513 distribution and number of terns (on the example of the lower Desna River). Vestnik zoologii 49

514 (5): 439-446. DOI 10.1515/vzoo-2015-0051

515 Bakaria F, Rizi H, Ziane N, Chabi Y, Banbura J. 2002. Breeding ecology of

516 whiskered terns in Algeria, North Africa. Waterbirds 25: 56-62.

517 Bakaria F, Benyacoub S, Gauthier-Clerc M, Banbura J. 2009. Long-term changes in the size,

518 structure and location of Whiskered Tern Chlidonias hybrida (L.) nest in deteriorating

519 environmental conditions of a North African Lake. Polish Journal of Ecology 57. 4: 749-759.

520 Bakaria F. 2013. Stratégies de la reproduction de la guifette moustac Chlidonias hybrida

521 (Pallas, 1811) dans le lac Tonga, wilaya d'El Tarf: Caractéristiques et qualité d'accueil de son

522 unique site nord-africain de reproduction. $\mathrm{PhD}$. Université Badji-Mokhtar- Annaba.

523 Barati A, Aliakbari A, Ghasempouri SM. 2011a. Variations in Breeding Success and Daily

524 Nest Survival of Whiskered Tern (Chlidonias hybrida) at Two Iranian Colonies. Russian Journal

525 of Ecology. Vol 42. No 4. 315-320. DOI 10.1134/S1067413611040059

526 Barati A, Ataei F, Esfandabad BS, Shabanian N, Etezadifar F. 2011b. Variations in nest-site

527 parameters in breeding waterbirds at Lake Zarivar, Western Iran. Avian Biology Research 4 (2).

528 87-92. 
529 Bayard TS, Elphick CS. 2011. Planning for sea-level rise: quantifying patterns of Saltmarsh

530 Sparrow (Ammodramus caudacutus) nest flooding under current sea-level conditions. The Auk

531 128.2 (2011): 393-403. doi: http://dx.doi.org/10.1525/auk.2011.10178

532 Betleja J, Skórka P, Zielińska M. 2007. Super-normal Clutches and Female-female Pairs in

533 Gulls and Terns Breeding in Poland. Waterbirds 30: 629-634.

534 Blanco JC, González JL. (eds). 1992. Libro rojo de los vertebrados de España. Colección

535 Técnica, ICONA, Madrid.

536 BirdLife 2004. Birds in Europe: population estimates trends and conservation status. Birdlife,

537 Cambridge.

538 Bollinger PB. 1988. Hatching asynchrony and factors influencing chick survival in the Common

539 Tern. M.Sc. Thesis, Cornell University, Ithaca, New York.

540 Braasch A, Schauroth C, Becker PH. 2009. Post-fledging body mass as a determinant of

541 subadult survival in Common Terns Sterna hirundo. Journal Ornithology 150: 401-407.

542 Brown CR, Brown MB. 1987. Group living in Cliff Swallows as an advantage in avoiding 543 predators. Behavior Ecological Sociobiology 21: 97-107.

544 Brunton DH. 1997. Impacts of predators: center nests are less successful than edge nests in a 545 large nesting colony of least terns. The Condor 99: 372-380.

546 Burger J, Shisler J. 1980. Colony and nest site selection in Laughing Gulls in response to tidal

547 flooding." Condor (1980): 251-258.

548 Callaghan P, Villaplana J. 1990. "El Fumarel cariblanco (Chlidonias hybrida) en el marjal de

549 Xeresa”. Ed. Testudo. Murcia. 259-270.

550 Carpentier A, Paillisson JM, Marion L. 2002. Fish-macrophyte interactions in littoral and 551 pelagic habitats of a eutrophic shallow lake: effects of vegetation shifts on the fish community.

552 In: Conservatoire du Patimoine Naturel de la Savoie (ed.) European Symposium of Management 553 and Conservation of Lake Littoral Vegetation. Conservatoire du Patrimoine Naturel de la Savoie.

554 Le Bourget-du-Lac. France. pp. 193-202.

555 Catry P, Tomé R, Cardoso AC. 1997. Biologia da reproduçao e estatuto da gavina-dos-pauis

556 Chlidonias hybridus no Paul do Boquilobo. Airo 8: 7-15.

557 Chapman-Mosher, BA. 1978. Factors influencing reproductive success and nesting strategies 558 in black terns, Thesis PhD. Univ. Fraser Simon USA. 154 p.

559 Cramp S, Simmons KEL. 1977. The Birds of the Western Palearctic Volume I. Oxford 
560 University Press, Oxford, New York, 722 pp.

561 Cramp S (Ed). 1985. The Birds of the Western Palearctic Volume IV. Oxford University Press,

562 Oxford, New York, 960 pp.

563 Dostine PL, Morton SR. 1989. Feeding ecology of the Whiskered tern, Chlidonias hybrida, in

564 the Alligator Rivers Region, Northern-Territory. Australian Wildlife Research 16 (5): 549-562.

565 Elkins N. 1996. Les oiseaux et la météo. Delachaux et Niestlé (Eds.), Paris: 214 p.

566 Gwiazda R, Ledwoń M. 2015. Sex-specific foraging behaviour of the Whiskered Tern

567 (Chlidonias hybrida) during the breeding season. Ornis Fennica 92: 15-22.

568 Glass GV, Peckham PD, Sanders JR. 1972. Consequences of failure to meet assumptions

569 underlying fixed effects analyses of variance and covariance. Rev. Educ. Res. 42: 237-288.

570 Lautrabe F. 2006. Biologie de la reproduction de la guifette moustac Chlidonias hibrida en

571 Brenne. Mémoire de l'Ecole Practique des hautes etudes. Université de Monpellier II,

572 Monpellier.

573 Lebreton JD, Hines JE, Pradel R, Nichols JD, Spendelow JA. 2003. Estimation by capture-

574 recapture of recruitment and dispersal over several sites. Oikos 101: 253-264.

575 Ledwoń M. 2011. Sexual size dimorphism, assortative mating and sex identification in the

576 whiskered tern Chlidonias hybrida. Ardea 99(2): 191-198.

577 Ledwoń M, Neubauer G, Betleja J. 2013. Adult and pre-breeding survival estimates of the

578 Whiskered Tern Chlidonias hybrida breeding in southern Poland. Journal of Ornithology (2013)

579 154:633-643. DOI 10.1007/s10336-012-0926-Z

580 Ledwoń M, Betleja J, Stawarczyk T, Neubauer G. 2014. The Whiskered Tern Chlidonias

581 hybrida expansion in Poland: the role of immigration. Journal Ornithol 155: 459-470. DOI $582 \quad 10.1007 / \mathrm{s} 10336-013-1027-3$

583 Ledwoń M, Betleja J, Neubauer G. 2015. An Effective method for trapping both parents and 584 chicks of Whiskered Tern (Chlidonias hybrida) and its impact on breeding success. Waterbirds 585 38(3): 290-295. DOI 10.1675/063.038.0309

586 Ledwoń M, Betleja J, Neubauer G. 2016. Different trapping schemes and variable disturbance 587 intensity do not affect hatching success of Whiskered Terns Chlidonias hybrida, Bird Study, 588 DOI: $10.1080 / 00063657.2015 .1136263$

589 Ledwoń M, Neubauer G. 2017. Offspring desertion and parental care in the Whiskered Tern 590 Chlidonias hybrida. Ibis (2017). doi: 10.1111/ibi.12496 
591 Lix LM, Keselman JC, Keselman HJ. 1996. Consequences of assumption violations revisited:

592 A quantitative review of alternatives to the one-way analysis of variance F test. Rev. Educ. Res. 593 66: 579-619.

594 Máñez M, Molina B, Pérez-Aranda D, Ibáñez F, García L, Garrido H. 2004. Fumarel común 595 Chlidonias niger. En, A. Madroño, C. González y J. C. Atienza (Eds.): Libro Rojo de las Aves 596 de España, pp. 259-261. Dirección General para la Biodiversidad-SEO/BirdLife. Madrid.

597 Mayfield HF. 1961. Nesting success calculated from exposure. Wilson Bull 73: 255-261.

598 Minias P, Janiszeski T, Lesner B. 2013. Center-periphery gradients of chick survival in the 599 colonies of Whiskered Terns Chlidonias hybrida may be explained by the variation in the 600 maternal effects of egg size. Acta Ornithologica 48:179-186.

601 Monticelli D, Ramos JA. 2012. Laying date, body mass and tick infestation of nestling tropical 602 Roseate Terns Sterna dougallii predict fledging success, first-year survival and age at first return 603 to the natal colony. Ibis 154: 825-837.

604 Muzinić J, Delić A. 1997. Nesting biology of Whiskered Tern Chlidonias hybridus in Croatia. 605 Avocetta 21: 165-168.

606 Nichols JD, Spendelow JA, Hines JE. 1990. Capture-recapture estimation of prebreeding 607 survival rate for birds exhibiting delayed maturation. Journal Field Ornithology 61: 347-354.

608 Nisbet ICT, Spendelow JA, Hatfield JS. 1995. Variations in growth of roseate tern nestling. 609 Condor 97: 335-344.

610 Ortiz A. 2005. "Colonia Tardía de Fumarel cariblanco en el marjal de Pego-Oliva”.

611 Revista Quercus. Junio 2005: 41-42.

612 Paillisson JM, Reeber S, Carpentier A, Marion L. 2006. Plant-water regime management in

613 wetland: consequences for a floating vegetation-nesting bird, whiskered tern Chlidonias

614 hybridus. Biodiversity and Conservation. 15: 3469-3480. DOI 10.1007/s10531-004-2939-2

615 Paillisson JM, Reeber S, Carpentier A, Marion L. 2007. Reproductive parameters in relation

616 to food supply in the whiskered tern Chlidonias hybrida. Journal of Ornithology. 148: 69-77.

617 DOI 10.1007/s10336-006-0102-4

618 Paillisson JM, Latraube F, Reeber S. 2008. Assessing growth and age of whiskered tern

619 Chlidonias hybrida nestling using biometrics. Ardea 96(2): 271-277. DOI 10.5253/078.096.0212

620 Quintana F, Yorio P. 1997. Breeding biology of royal and cayenne terns al a mixed-species 621 colony in Patagonia. Wilson Bulletin. Fort Collins 109(4): 650-662. 
622 Rizi H. 1994. Caractérisation de l'écologie de reproduction de la Guifette moustac Chlidonias 623 hybrida (Pallas), dans le Parc National d'El Kala (Wilaya d'E1 Tarf). Ingéniorat d'état, Université 624 de Annaba.

625 Spina F. 1982. Contribution to the breeding biology of the whiskered tern Chlidonias hybrida in 626 Val Campotto (Northern Italy). Avocetta 6: 23-33.

627 Spendelow JA, Nichols JD, Nisbet ICT, Hays H, Cormons GD, Burger J, Safina C, Hines 628 JE, Gochfeld M. 1995. Estimating annual survival and movement rates of adults within a 629 metapopulation of Roseate Terns. Ecology 76: 2415-2428.

630 Stienen EWM, Brenninkmeijer A. 2002. Variation in growth in sandwich terns Sterna

631 sandvicensis and the consequences for pre and post-fleding mortality. Ibis 144: 567-576.

632 Tomialojć L. 1994. Whiskered tern. In: Tucker, G.M. \& Heath, M.F (eds) Birds in Europe. Birds 633 in Europe: their Conservation Status. Birdlife International (Birdlife Conservation Series 3)

634 Cambridge, pp. 302-303.

635 Tucker GM, Heath MF. 1994. Birds in Europe: their Conservation Status. Birdlife International 636 Cambridge. UK.

637 Urios V, Escobar JV, Pardo R, Gomez JA. 1991. "Atlas de las aves nidificantes de la 638 Comunidad Valenciana". Ed. Generalitat Valenciana. Conselleria d'Agricultura i Pesca.182-183. 639 Urios V, Donat MP, Viñals MJ. 1993. La marjal de Pego-Oliva. El medi natural de la marjal de 640 Pego-Oliva i el seu entorn. Institut d'estudis comarcals de la Marina Alta. Pedreguer. Alicante.

641 Van de Pol M, Ens BJ, Heg D, Brouwer L, Krol J, Maier M, Exo KM, Oosterbeek K, Lok 642 T, Eising CM, Koffijberg K. 2010. Do changes in the frequency, magnitude and timing of 643 extreme climatic events threaten the population viability of coastal birds?. Journal of Applied 644 Ecology 47: 720-730. DOI: 10.1111/j.1365-2664.2010.01842.x

645 Wiklund CG, Andersson M. 1994. Natural selection of colony size in passerine bird. Journal 646 Animal of Ecology 63: 765-774.

647 Villaplana J. 1984. Dades sobre nidificació del Fumarell cariblanc als marjals de Xeresa. Ullal 648 5: 27-32.

649 Wittenbergejr E, Hunt Jr.GL. 1985. The adaptive significance of coloniality in birds, p. 1-78.

650 In D. S. Farner. J. R. King and K. C. Parkes (eds.), Avian biology. Vol. 8. Academic Press, New 651 York. 


\section{Figure 1}

Distribution map of the 5 sampling areas

Distribution map of the 5 sampling areas from North to South of the Valencian Community, with the approximate distance (in kilometers) in a straight line between the wetlands studied. The Albufera of Valencia is not a sampling area, it is a resting and feeding area at the end of the reproductive season.

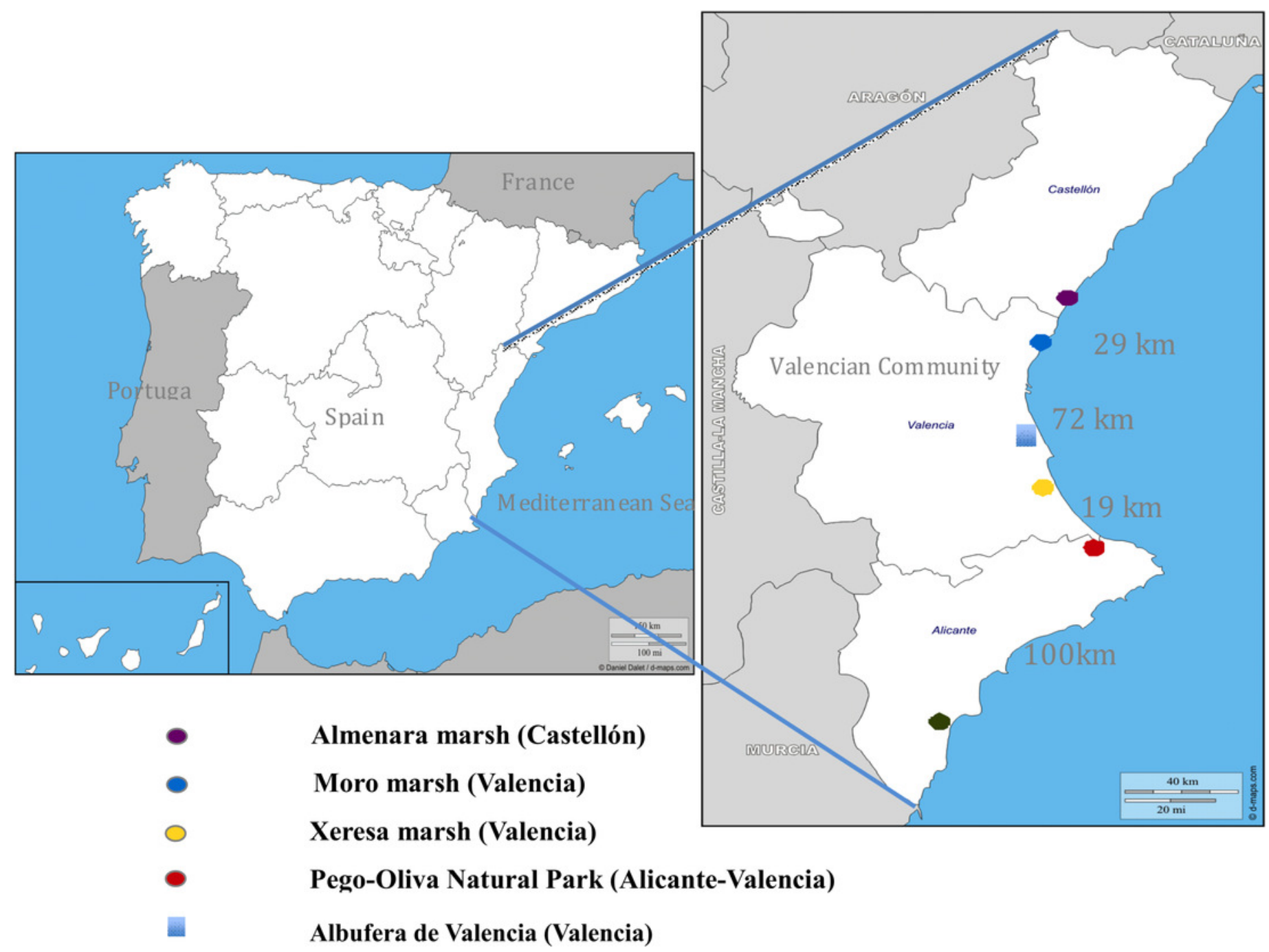




\section{Figure 2}

Forms and composition of Whiskered tern nests with various qualities of structure ( $A$ : high, B and C: medium \& D: low quality).

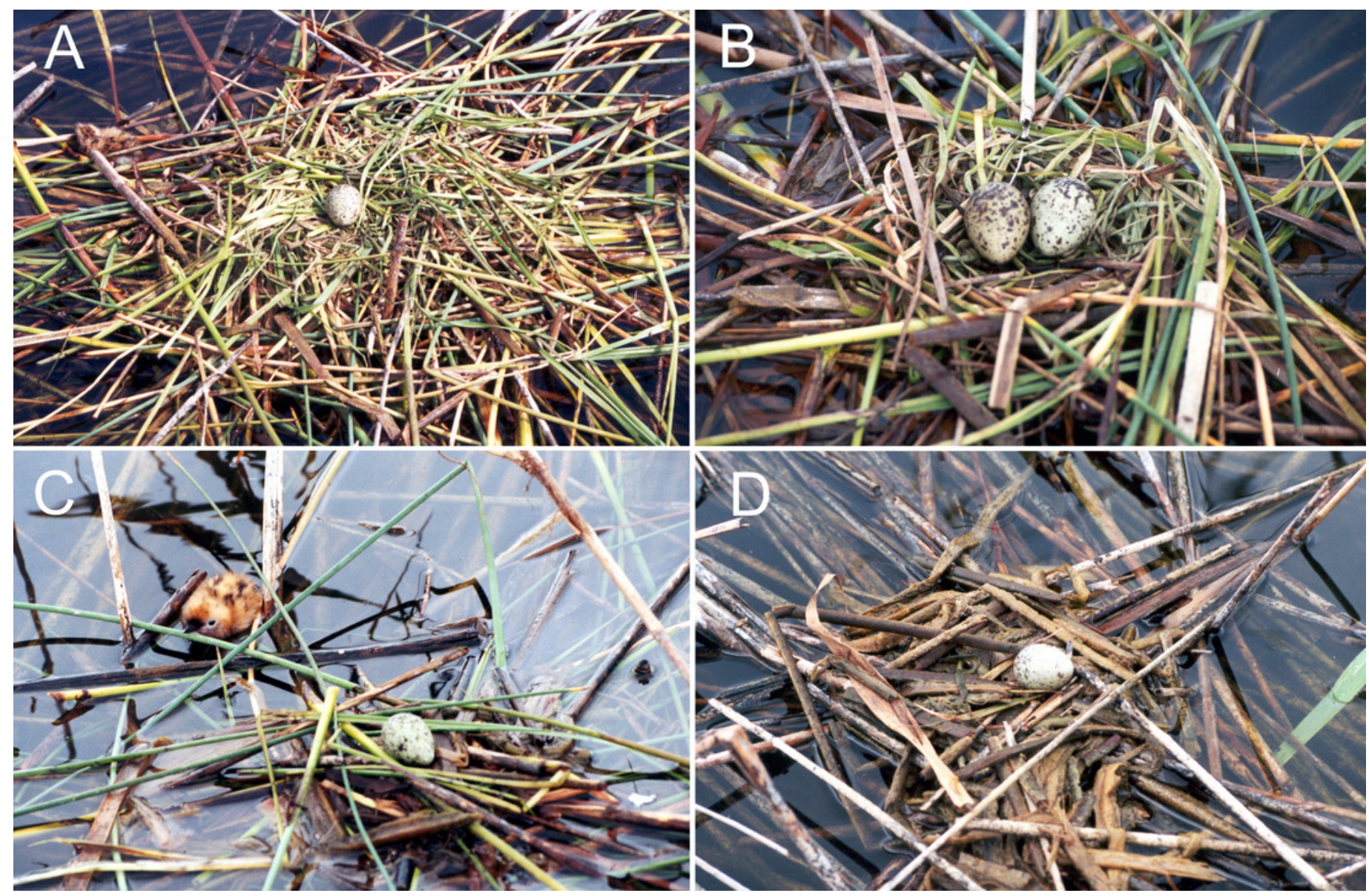


Figure 3

Hatching, fledgling and breeding success mean in Pego-Oliva N.P. (2002-2009).

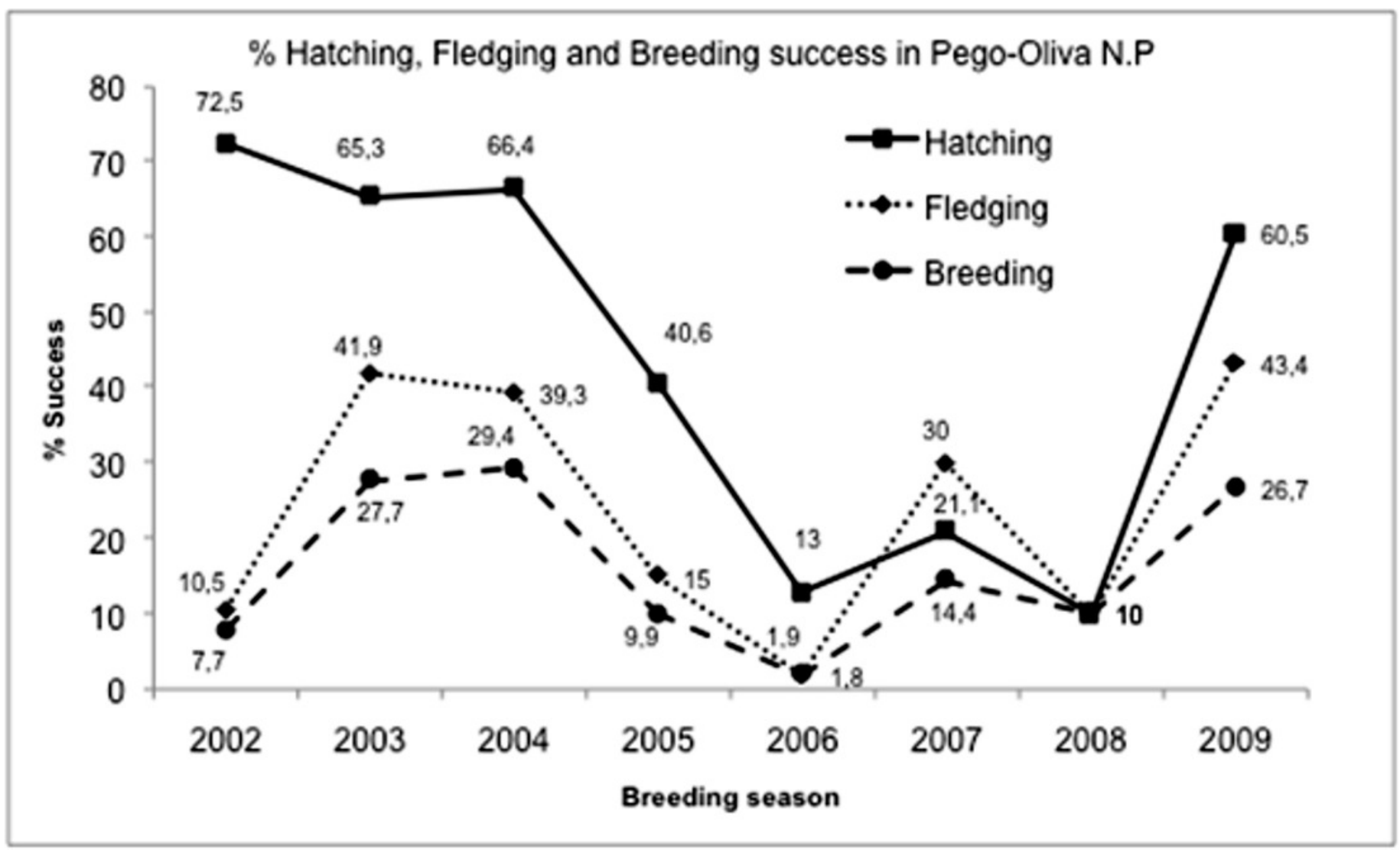


Figure 4

Percentage of hatching, fledgling and breeding success according to the anchoring depth of nests $(A, B \& C)$ and the average fluctuation rate $(D, E, \& F)$ for the data set. 

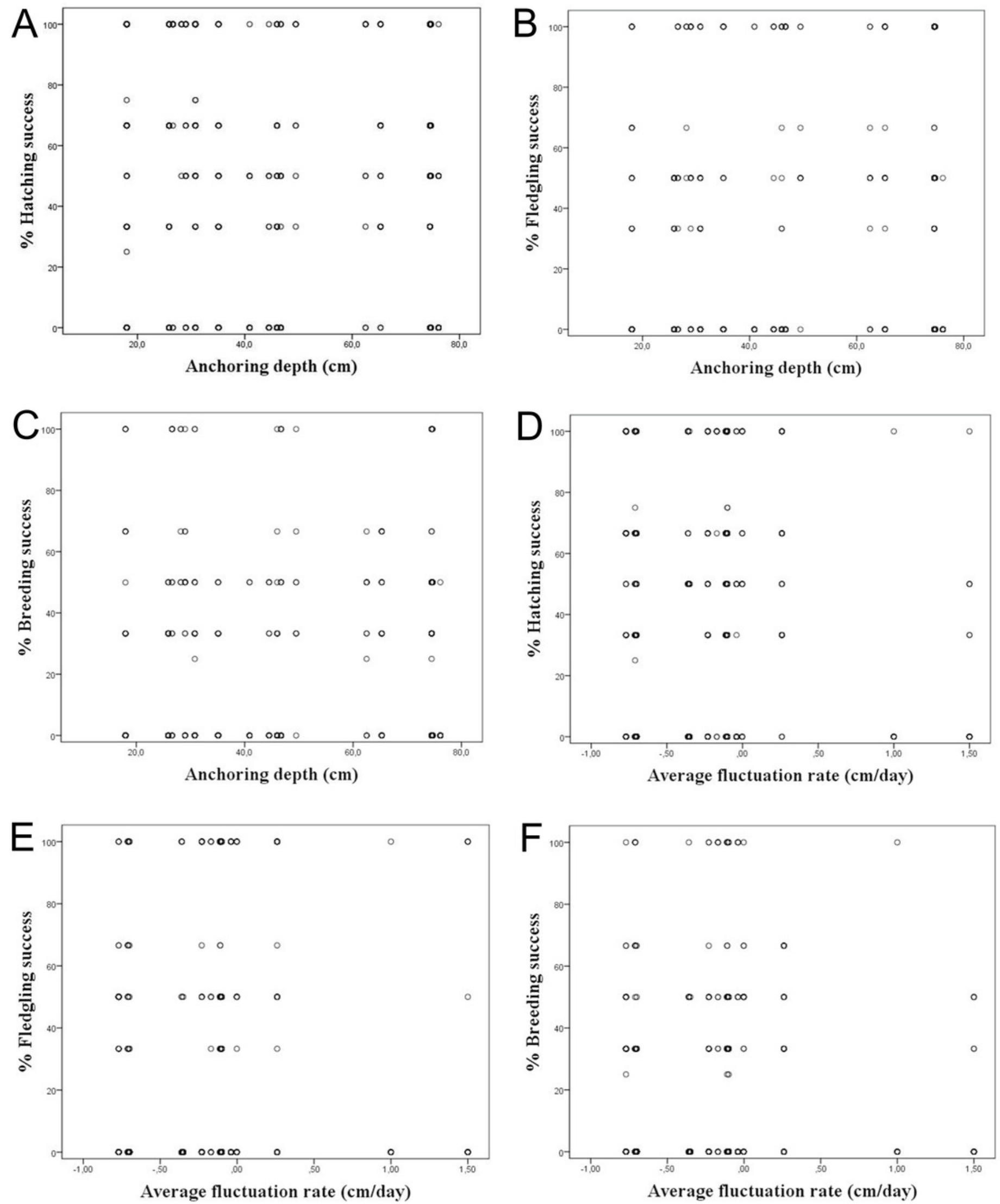


\section{Figure 5}

A nest of Whiskered Tern of high quality that was destroyed by the water level fluctuation.

A : nest with 3 eggs with a high quality over macrophytes; $B$ : nest destroyed by the rise of water level fluctuation.
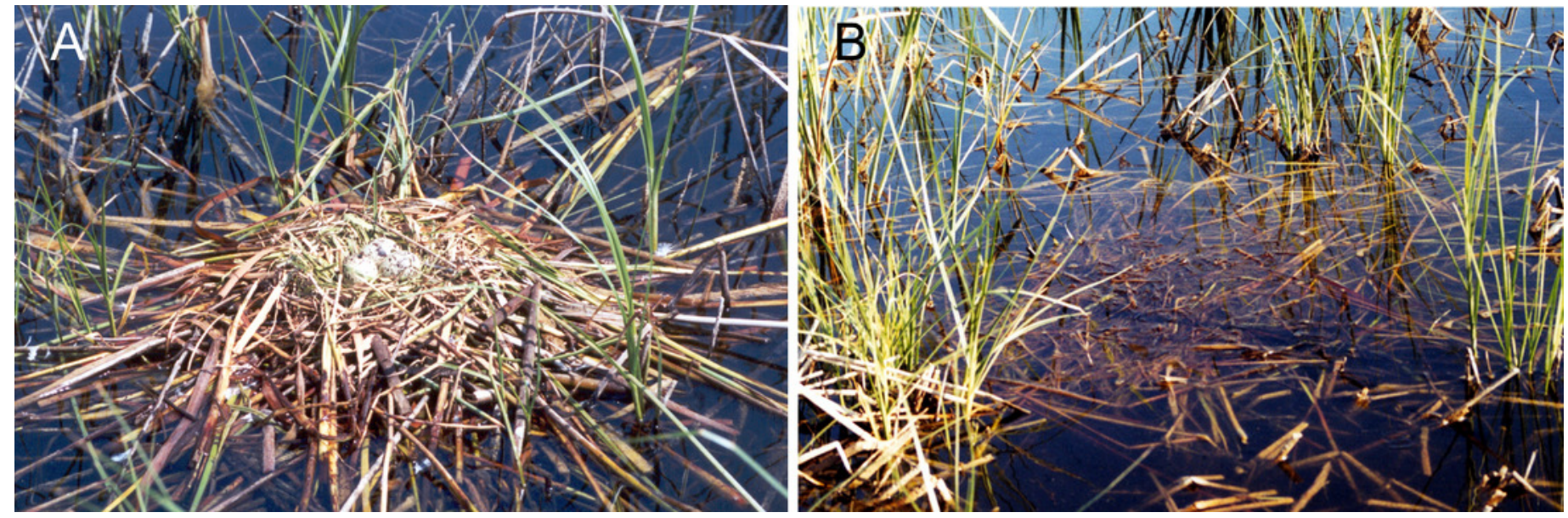


\section{Table $\mathbf{1}$ (on next page)}

Breeding parameters of Whiskered Tern Chlidonias hybrida

Breeding parameters of Whiskered Tern Chlidonias hybrida in the studied wetlands of Valencian Community (2002-2009) and maximum fluctuation of the water level (with mean of increasing and decreasing water level ranges). 


\begin{tabular}{|c|c|c|c|c|c|c|c|c|}
\hline Year & $\begin{array}{c}\text { Colon } \\
\mathbf{y} \\
\mathbf{N}^{\mathbf{o}}\end{array}$ & Area & $\begin{array}{c}\mathbf{N}^{\mathbf{o}} \\
\text { Nest }\end{array}$ & $\begin{array}{c}\text { Mean } \\
\text { Nest depth } \\
\text { (cm) } \\
\text { (SD) }\end{array}$ & $\begin{array}{c}\% \\
\text { Hatching } \\
\text { Success } \\
\text { (SD) }\end{array}$ & $\begin{array}{c}\% \\
\text { Fledgling } \\
\text { Success } \\
\text { (S D) }\end{array}$ & $\begin{array}{c}\% \\
\text { Breeding } \\
\text { Success } \\
\text { (SD) }\end{array}$ & $\begin{array}{c}\text { Maximum } \\
\text { Fluctuatio } \\
\mathbf{n} \\
\text { colony } \\
\text { (cm) }\end{array}$ \\
\hline 2002 & 1 & Pego & 111 & $30,8 \pm 0,8$ & $72,5 \pm 35,4$ & $10,5 \pm 24,3$ & $7,7 \pm 17,5$ & 10 \\
\hline 2003 & 2 & Pego & 64 & $74,5 \pm 1,5$ & $65,3 \pm 28,7$ & $41,9 \pm 38,6$ & $27,7 \pm 27$ & -5 \\
\hline 2004 & 3 & Pego 1 & 79 & $25,9 \pm 5,1$ & $58,9 \pm 38$ & $13 \pm 21,3$ & $10 \pm 16,4$ & 14 \\
\hline 2004 & 4 & Pego 2 & 13 & $62,5 \pm 12,6$ & $63,3 \pm 42,2$ & $46,7 \pm 37,5$ & $32,5 \pm 25$ & -23 \\
\hline 2004 & 5 & Pego 3 & 8 & $49,5 \pm 6$ & $77,1 \pm 26,6$ & $58,3 \pm 32,1$ & $45,8 \pm 29,2$ & -15 \\
\hline 2004 & 6 & Hondo & 77 & $46 \pm 14,2$ & $18,9 \pm 29,4$ & $7,2 \pm 23,9$ & $4,2 \pm 13,1$ & -30 \\
\hline 2004 & 7 & Moro 1 & 50 & $35,1 \pm 2,8$ & $44,8 \pm 35$ & $19,8 \pm 38,2$ & $8,7 \pm 16,5$ & -10 \\
\hline 2004 & 8 & Moro 2 & 5 & $28,2 \pm 3,9$ & $90 \pm 22,4$ & $83,3 \pm 23,6$ & $73,3 \pm 25,3$ & -11 \\
\hline 2005 & 9 & Pego 1 & 18 & $40,9 \pm 3,2$ & $20 \pm 31,6$ & $13,3 \pm 35,2$ & $6,7 \pm 17,6$ & -8 \\
\hline 2005 & 10 & Pego 2 & 25 & $74,2 \pm 6,7$ & $61,1 \pm 42,8$ & $13,9 \pm 28,7$ & $11,1 \pm 21,4$ & -16 \\
\hline 2005 & 11 & Xeresa & 114 & $18 \pm 8,9$ & $43,2 \pm 41,8$ & $10,8 \pm 26,8$ & $9,2 \pm 23,5$ & -20 \\
\hline 2005 & 12 & Moro & 30 & $46,7 \pm 0,6$ & $21,8 \pm 34$ & $20,7 \pm 41,2$ & $15,5 \pm 33$ & -1 \\
\hline 2006 & 13 & Pego & 27 & $75 \pm 14,1$ & $13 \pm 26,3$ & $1,9 \pm 9,6$ & $1,8 \pm 9,6$ & -20 \\
\hline 2007 & 14 & Pego & 38 & $54,5 \pm 7,8$ & $21,1 \pm 30,5$ & $30 \pm 45,5$ & $14,4 \pm 21,7$ & -6 \\
\hline 2008 & 15 & Pego & 10 & $49 \pm 1,4$ & $10 \pm 31,6$ & $10 \pm 31,6$ & $10 \pm 31,6$ & 8 \\
\hline 2008 & 16 & Almenar & 12 & $26,6 \pm 2,3$ & $80,6 \pm 38,8$ & $48,6 \pm 42,9$ & $47,2 \pm 43,1$ & -6 \\
\hline 2009 & 17 & Pego & 64 & $25,5 \pm 15,2$ & $60,5 \pm 30,2$ & $43,4 \pm 43,2$ & $26,7 \pm 26,1$ & 6 \\
\hline 2009 & 18 & Moro & 32 & $31 \pm 3,1$ & $62,5 \pm 38,2$ & $46,7 \pm 41,4$ & $35 \pm 29,6$ & 3 \\
\hline $\begin{array}{c}\text { Mean } \\
( \pm \text { SD }\end{array}$ & & & $\begin{array}{l}43,2 \\
\pm 34 \\
5\end{array}$ & $44,1 \pm 18,2$ & $49 \pm 25,8$ & $29,1 \pm 21,9$ & $21,8 \pm 18,9$ & $\begin{array}{r}\text { Rank Mean } \\
+8,2 \pm 4,1 \\
-12,7 \pm 8,2\end{array}$ \\
\hline
\end{tabular}




\section{Table 2 (on next page)}

Statistics of Kruskal-Wallis tests used to check the differences in the percentage of hatching, fledgling and breeding success according to the study areas.

The chi-square value, degrees of freedom and $p$-value are shown for each test. 


\begin{tabular}{|c|c|c|c|}
\hline & $\begin{array}{c}\text { \% Hatching } \\
\text { success }\end{array}$ & $\begin{array}{c}\% \text { Fledgling } \\
\text { success }\end{array}$ & $\begin{array}{c}\% \text { Breeding } \\
\text { success }\end{array}$ \\
\hline$\chi^{2}$ & 62.405 & 34.440 & 36.577 \\
\hline df & 4 & 4 & 4 \\
\hline $\mathbf{P}$ & $<0.000$ & $<0.000$ & $<0.000$ \\
\hline
\end{tabular}




\section{Table 3(on next page)}

\section{Statistics}

Statistics of the linear regressions between the anchorage depth for nests $(\mathrm{cm})$ and the percentage of Hatching, Fledgling and Breeding Success, and between the average fluctuation rate (cm/day) and the percentage of hatching, fledgling and breeding success. The coefficient of correlation $(R)$, the coefficient of determination $\left(R^{2}\right)$ and the standard error are shown for each regression. For Hondo, Xeresa and Almenara is not possible doing a linear regression because there is not enough data. 


\begin{tabular}{llcccccr} 
& & \multicolumn{3}{c}{ Anchoring depth } & \multicolumn{3}{c}{ Fluctuation rate } \\
\cline { 3 - 8 } & & $\mathbf{R}$ & $\mathbf{R}^{2}$ & Standard Error & $\mathbf{R}$ & $\mathbf{R}^{2}$ & Standard Error \\
\cline { 3 - 8 } All Data & \% Hatching success & 0.041 & 0.002 & 40.345 & 0.007 & 0.000 & 40.378 \\
& \% Fledgling success & 0.173 & 0.030 & 33.955 & 0.162 & 0.026 & 34.023 \\
& \% Breeding success & 0.129 & 0.017 & 24.835 & 0.119 & 0.014 & 24.867 \\
\hline \multirow{3}{*}{ Pego } & \% Hatching success & 0.112 & 0.013 & 38.619 & 0.163 & 0.027 & 38.344 \\
& \% Fledgling success & 0.253 & 0.064 & 33.214 & 0.090 & 0.008 & 34.192 \\
& \% Breeding success & 0.228 & 0.052 & 23.207 & 0.035 & 0.001 & 23.819 \\
\hline \multirow{2}{*}{ Moro } & \% Hatching success & 0.441 & 0.194 & 35.065 & 0.091 & 0.008 & 38.906 \\
& \% Fledgling success & 0.233 & 0.054 & 40.925 & 0.097 & 0.009 & 41.886 \\
& \% Breeding success & 0.247 & 0.061 & 28.625 & 0.18 & 0.032 & 29.056 \\
\hline
\end{tabular}




\section{Table 4 (on next page)}

Percentages Nest, Eggs and Chicks lost during the sampling period.

Eggs, Chicks and Fledglings in the colonies. The percentages of mean Eggs and Chicks loss. And percentages $( \pm S D)$ of Nest, Eggs and Chicks lost during the sampling period. 


\begin{tabular}{|c|c|c|c|c|c|c|c|c|c|}
\hline Colony & Year & $\begin{array}{c}\% \\
\text { Mean } \\
\text { Nest loss } \\
\text { Sampling }\end{array}$ & $\begin{array}{c}\% \\
\text { Mean } \\
\text { Eggs loss } \\
\text { Sampling }\end{array}$ & $\begin{array}{c}\% \\
\text { Mean } \\
\text { Chicks loss } \\
\text { Sampling }\end{array}$ & $\begin{array}{c}\mathbf{N}^{\circ} \\
\text { Eggs/ } \\
\text { colony }\end{array}$ & $\begin{array}{c}\% \\
\text { Eggs } \\
\text { loss/ } \\
\text { colony }\end{array}$ & $\begin{array}{c}\mathrm{N}^{\mathbf{o}} \\
\text { Chicks } \\
\text { /colony }\end{array}$ & $\begin{array}{c}\% \\
\text { Chicks } \\
\text { loss } \\
\text { colony }\end{array}$ & $\begin{array}{c}\mathrm{N}^{\mathbf{o}} \\
\text { Fledglins } \\
\text { / colony }\end{array}$ \\
\hline & & $\mathrm{X} \pm \mathrm{SD}$ & $\mathrm{X} \pm \mathrm{SD}$ & $\mathrm{X} \pm \mathrm{SD}$ & & & & & \\
\hline Pego & 2002 & $27,67 \pm 16,37$ & $29,51 \pm 39,8$ & $76,14 \pm 12,68$ & 193 & 32,12 & 131 & 86,3 & 18 \\
\hline Pego & 2003 & $1,82 \pm 2,5$ & $24,9 \pm 31,24$ & $36,02 \pm 25,97$ & 171 & 36,84 & 108 & 60,2 & 43 \\
\hline Pego 1 & 2004 & $28,72 \pm 25,52$ & $28,60 \pm 31,01$ & $49,93 \pm 37,4$ & 225 & 25,00 & 133 & 83,5 & 22 \\
\hline Pego 2 & 2004 & $17,57 \pm 15,79$ & $14,94 \pm 21$ & $50 \pm 44,72$ & 23 & 40,89 & 15 & 46,7 & 8 \\
\hline Pego 3 & 2004 & $7,5 \pm 16,77$ & $5,72 \pm 12,79$ & $6,2 \pm 8,53$ & 20 & 34,78 & 15 & 40,0 & 9 \\
\hline Hondo & 2004 & $37,76 \pm 22,53$ & $46,9 \pm 32,49$ & $40,45 \pm 22,03$ & 172 & 81,98 & 31 & 74,2 & 8 \\
\hline Moro 1 & 2004 & $19,14 \pm 15,22$ & $28,34 \pm 19,82$ & $28,94 \pm 16,42$ & 118 & $\begin{array}{l}55,08 \\
\end{array}$ & 53 & 79,2 & 11 \\
\hline Moro 2 & 2004 & $8 \pm 17,89$ & $14,3 \pm 20,22$ & $11,1 \pm 19,23$ & 11 & 9,09 & 10 & 20,0 & 8 \\
\hline Pego 1 & 2005 & $18,6 \pm 38,17$ & $30,06 \pm 39,62$ & 33,3 & 32 & 81,25 & 6 & 66,7 & 2 \\
\hline Pego 2 & 2005 & $19,2 \pm 42,93$ & $30,82 \pm 39,18$ & $15,85 \pm 2,19$ & 38 & 36,84 & 24 & 83,3 & 4 \\
\hline Xeresa & 2005 & $24.80 \pm 42,15$ & $28,72 \pm 40,04$ & $41,63 \pm 33,04$ & 298 & 57,38 & 127 & 79,5 & 26 \\
\hline Moro & 2005 & $61,65 \pm 30,62$ & $74,55 \pm 35,99$ & $12,5 \pm 17,68$ & 59 & 77,97 & 13 & 30,8 & 9 \\
\hline Pego & 2006 & $31,1 \pm 35,3$ & $45 \pm 39,69$ & 14,3 & 50 & 86,00 & 7 & 85,7 & 1 \\
\hline Pego & 2007 & 50 & 41,2 & 71,4 & 34 & 79,41 & 7 & 28,6 & 5 \\
\hline Pego & 2008 & 90 & 90 & 0 & 20 & 90,00 & 2 & 0,0 & 2 \\
\hline Almenara & 2008 & $9,72 \pm 15,28$ & $13,15 \pm 9,58$ & $6,18 \pm 12,01$ & 28 & 21,43 & 22 & 50,0 & 11 \\
\hline Pego & 2009 & 0 & $13,6 \pm 7,64$ & 20 & 79 & 43,04 & 45 & 51,1 & 22 \\
\hline Moro & 2009 & $6,67 \pm 11,55$ & $16,7 \pm 21,09$ & $28,59 \pm 24,76$ & 47 & 40,43 & 28 & 42,9 & 16 \\
\hline TOTAL & $\mathbf{X} \pm$ & $25,60 \pm$ & $32,06 \pm$ & 31,91 \pm & $89,9 \pm$ & $51,64 \pm$ & $43,2 \pm$ & $56,0 \pm$ & $12,5 \pm$ \\
\hline
\end{tabular}




\section{Table 5 (on next page)}

Statistics of Kruskal-Wallis tests used to check the differences in the percentage of nests, eggs and chicks loss between the colonies and between the years.

Differences between the years only for Pego.Oliva N.P. and Moro marsh areas are also tested (the only ones that data are available for different years). The chi-square value, degrees of freedom and $p$-value are shown for each test. 


\begin{tabular}{lrrrr}
\multirow{3}{*}{ Colonies } & & \% Nest loss & \% Eggs loss & \% Chicks loss \\
\cline { 3 - 5 } & $\chi^{2}$ & 32.336 & 17.284 & 19.484 \\
& $\mathrm{df}$ & 13 & 13 & 12 \\
\multirow{3}{*}{ Years } & $\mathrm{P}$ & 0.002 & 0.187 & 0.078 \\
& $\chi^{2}$ & 16.919 & 4.766 & 15.924 \\
& $\mathrm{df}$ & 7 & 7 & 7 \\
\multirow{3}{*}{ Pego } & $\mathrm{P}$ & 0.018 & 0.689 & 0.026 \\
& $\chi^{2}$ & 19.557 & 8.488 & 6.87 \\
& $\mathrm{df}$ & 7 & 7 & 6 \\
\multirow{3}{*}{ Moro } & $\mathrm{P}$ & 0.007 & 0.292 & 0.333 \\
& $\chi^{2}$ & 4.653 & 3.773 & 0.563 \\
& $\mathrm{df}$ & 2 & 2 & 2 \\
\hline
\end{tabular}

